\title{
Optics teaching: new contents and methods
}

\author{
Alfredo Yeras, Rolando Gonzalez Pena
}

Alfredo Moreno Yeras, Rolando Gonzalez Pena, "Optics teaching: new contents and methods," Proc. SPIE 3831, Sixth International Conference on Education and Training in Optics and Photonics, (16 June 2000); doi: $10.1117 / 12.388744$ 


\title{
Optics teaching: new contents and methods.
}

\author{
Alfredo Moreno Yeras, Rolando González Peña. \\ Physics Department, Higher Institute of Technology "José Antonio Echeverría". \\ CP 19390, Havana, CUBA
}

\begin{abstract}
The pedagogical implementation of new optical contents inclusion in the curricula of Technical Sciences University Courses is presented in this paper. The application of updated pedagogical trends enables the development of a pedagogical system in the Optics teaching that contributes to the achievement of a qualitatively higher teaching-learning process.
\end{abstract}

Keywords: teaching, Physics teaching, optical techniques, pedagogical trends.

\section{INTRODUCTION}

The fast and growing development of Science and Technology imposes the application of new strategies for the training of specialists at universities. That's why it is necessary to take into account the process of updating contents and methods, achieving a close link between contents and speciality topics, and developing research habits and skills for improving the teaching-learning process and increasing graduate quality and excellence.

Very important optical measuring techniques have been developed during the recent technological advances, so it is necessary to include the study of these techniques in the future engineering studies.

A set of optical measuring techniques is proposed to be introduced for the checking or testing of material behavior in different situations without affecting the physical properties of materials. These techniques are based on different physical processes concerning light, thus there is a great variety of types and applications of these techniques in solving sociopractical problems.

The physical processes used as the basis of most of these techniques, are taken into account in the basic objective-contentskill system in all the specialities concerning Technical Sciences studied at the Higher Institute of Technology "José Antonio Echeverría“ (ISPJAE).

The pedagogical implementation of these activities took into consideration the latest discoveries of the up to date pedagogical trends such as the socio-historical approach, emphasizing the social role in the acquisition and development of knowledge, and also the most recent findings of the cognitive pedagogical theory regarding the steps and actions constituting the learning process and the features and applications concerning transference of skills, sense and meaning of background and recently acquired knowledge.

Aiming at contributing to the students' achievement of research habits and skills, advanced technologies are proposed to be included in the engineering study syllabus. It is also proposed the possibility of having students able of researching on their speciality topics independently, students should be able of using a system of optical measuring techniques adapted to their specialities appropriately.

Seminars, specialized-laboratory classes, and workshops, were the pedagogical activities mainly used for achieving the required development of the proposed skills. Recently the non destructive testing laboratory at the Higher Institute of Technology "José Antonio Echeverría“(ISPJAE) has developed and applied a set of optical techniques included in the teaching-learning activities in different specialities at ISPJAE. 
The present paper shows the general features of the optical techniques used in this laboratory, and the implementation ways of the teaching-learning activities in the different specialities of Science and Technology.

\section{DEVELOPMENT}

The updating of contents and teaching ways concerning the latest knowledge and advanced technologies in the engineering studies, not only in the professional field but also in the pedagogical one contributes to the updating of engineering curriculum.

The appropriate links between General Physics contents and the different engineering specialities are achieved by the specialization of the teaching-learning process linking Physics contents and the developing professional profile tasks and problems.

The involvement of socio-practical problems in the teaching-learning process contributes to the development of scientific research habits and skills because students have to devote time and creativity to look for the solution of the assigned scientific problems and tasks.

The consideration of optical measuring techniques in the Optics contents involved in all the specialities of Science and Technology contributes to the achievement of the above purposes because they are applied in all engineering specialities and are based on physical basis involved in the engineering curriculum.

The organization of the teaching-learning process takes into account the discoveries of the socio-historical and cognitive approach. The structure, design and implementation of this process in the Optics contents teaching in the syllabus of Physics in the different engineering specialities by means of the application of the optical measuring techniques is based on the scientific foundations provided by the socio-historical and cognitive theories.

An essential aspect considered in the teaching-learning process is the knowledge-subject role in his interrelation with the surrounding objective reality, motivated by the interaction objectives, i.e. action and motivation are closely linked in the activity' implementation. Hence, the teaching-learning activity development is the pedagogical system constituent wich is vital for keeping motivation alive regarding Physics contents learning.

First of all, the objectives are designed in terms of professional tasks related with the professional profile of each engineering speciality for the Optics teaching-learning process. The objective-contents-skills system is proposed in accordance with the required professional tasks of each engineering profile.

All engineering specialities curricula are characterized by the light phenomena study involving point or wave modellation in these phenomenon interpretations, besides these light phenomena, the physical basis of many optical measuring techniques are also proposed in this paper.

The non destructive testing laboratory is designed for developing scientific and technical research habits and skills, independent ways of approaching and solving professional tasks and strengthening Physics particular contents in different specialities in Science and Technology.

The laboratory structure is based on the introduction and application of non-destructive testing used in different engineering branches. These tests are used for solving problems concerned with the different specialities, such as optical, mechanical and nuclear testing.

Since the light interference, diffraction and polarization are present in the physical essence of all optical measuring techniques applied in the non destructive testing laboratory, these techniques are grouped into:

- Interferometrical techniques,

- Difractometrical techniques,

- Polarimetrical techniques. 
Interferometrical techniques are based on the light interference phenomena and may be applied for the:

- Surface quality and property control,

- Refraction index measurement,

- Displacement measurement,

- Stress and strain determination and so on.

Techniques measuring accurately parameters using classical interference or thin-sheet interference systems are included in these optical techniques.

Double-exposure speckle photography is an optical measuring technique concerned with alleatory interference presented in rough surface reflection. It consists in overlapping two speckle patterns corresponding to two different states of the object to be studied on the same photographic film. The speckle photography analysis enables the assessment of the changes taking place in objects under the effect of an external action.

This technique is widely used in the displacement and strain measurement and it is also useful for assessing the stress distribution on bodies under load.

Difractometrical techniques are based on light diffraction phenomena and are applied in

- thickness measurements,

- microobjects size measurements,

- material characterization and so on.

Techniques based on a simple experimental system for studying the diffraction phenomenon are included in the difractometrical techniques: They may be used for measuring thickness, particles and holes diameters and so on. The techniques used for supporting spectroscopical spectrum measurement and substance characterization are also included in the difractometrical techniques.

An advanced optical measuring technique is the holographic interferometry, which is based on the physical principles concerned with interference and diffraction phenomena. Holographic interferometry is an application of holography using the reproduction of the light wave from the object without being affected and interfering with the wave from the strained object under the external agent action. An interference pattern is formed in reconstructing the interferogram. The pattern is formed by dark and bright fringes enabling the assessment of differences of the strained and unstrained object, and the linking with the actions acting on the object.

This technique is widely used in the measurement of displacement, strain and stress fields of objects under different loading actions.

The polarimetrical techniques are based on the light polarization phenomenon and are used for

- solute concentration determination,

- stress state and strain determination,

- refraction index measurement,

- displacement measurement, and so on.

Techniques based on optical activity phenomenon are included in the polarimetrical techniques. There are also other techniques based on the reflection polarization, such as the ellipsometry, and other techniques related with the artificial anisotropy.

The so-called photoelastic technique is an example of the techniques based on artificial anisotropy. These techniques are based on the properties of some transparent materials, which behave as anisotropic materials when subjected to external forces. The photoelasticity theory shows a link between the refraction indexes of photoelastic substances and the magnitude 
and direction of the stress state acting on the material. That's why the testing is constituted by the model design of photoelastic materials at reduced or normal scale and the study of the model behavior under external actions.

The organization of pedagogical exhibitions is an alternative way of promoting student motivation. These exhibitions may be organized using a minimum of resources for showing in a nice way some of the Optics contents regarding a particular topic. In the Physics Department at ISPJAE it was designed and shown a pedagogical exhibition on Holography, which was used for the teaching of Optics contents in different engineering specialities.

The historical development of Holography, the physical and mathematical principles used in Holography, the experimental characteristics of this technique, some defects which may be detected in hologram construction as well as some of the principal holograms done at the Physics Department concerning this research line are shown in this exhibition. A set of pictures, holograms and documents is used for showing this topic development and linking Holography with the engineering specialities.

The addition of these new contents may be achieved not only by means of the introduction of optical testing in teachinglearning activities used in the different subjects constituting Physics. These subjects are taught at the different engineering specialities and they may include other methodological alternatives.

The use of one of these alternatives at the non destructive testing laboratory has been implemented by the optional course about non destructive optical testing offered for complementing the engineering student habits and skills. This course is divided into two levels:

First Level: The objectives of the course are describing and characterizing the main features of testing, applications, and elemental physical models for each type of testing in an independent way. The tests to be studied are grouped into: interferometrical, diffractometrical, and polarimetrical tests. The required knowledge-habit and skill system, time, and evaluation are designed in accordance with the objective system.

Second Level: The objectives of the course are describing, designing and using research methods in the application of testing for solving some socio-practical problems concerning the professional profile. The required knowledge- habit and skill system, time, and evaluation are designed in accordance with the objective system, in such a way that students may increase their knowledge about research methodology, experimental data treatment, and application of the previous knowledge in a research paper.

In the two levels of this course, seminars and teamwork are commonly used as alternatives for contributing to the increase of the potential learning of students under the influence of the collective support. These cognitive alternatives exert a strong influence on the zone of proximal development of students. The accurate and early detection of this zone and the application of pedagogical strategies to enhance collaborative learning has contributed a lot to the achievement of the pedagogical aims.

The contextualized teaching-learning method is a suitable alternative for increasing motivation and quality in the teachinglearning process. This alternative consists in linking engineering-profile topics with Physics contents, aimed at enhancing engineering student cognitive possibilities, motivation and skills. A context may be defined as a concrete situation, which is significant for the subject contents, or speciality. This context acts as the connecting thread for the presentation, development and assessment of the traditional contents or topics to be taught. Holography has been considered as an interesting context.

The application of Holography as a teaching context is being designed as a project to be tested in a near future at ISPJAE. In the project design a hierarchical organization of knowledge and basic concepts is proposed to be followed in this context. Holography context is proposed for the acquisition of knowledge concerned with wave Optics. The contents are organized into three groups:

1- Light radiation. Origin and main features.

2- Radiation overlapping. Hologram register.

3- Light propagation through substances. Hologram reconstruction. 
The basic contents of radiation, radiation properties, radiation overlapping, coherence, interference, diffraction and so on are included in the above groups.

In a concrete way it may be summarized that:

1- Optical testing enables the characterization and determination of displacements, sizes, strains, optical properties and so on, i.e. it is possible the assessment of a set of parameters and physical properties in substances concerned with all engineering specialities.

2- Analyzing the engineering syllabus it may be concluded that the introduction of topics explaining basic phenomena in optical testing enables the attainment of the necessary profile for future engineers.

3- Optical testing may be included in traditional as well as in other types of teaching-learning activities involved or not in the syllabus design.

The significance of the involvement of physical testing in the different Physics syllabus design for engineering specialities has been demonstrated. It contributes to the continuous improvement of the teaching-learning process and the growing motivation and excellence of engineering graduates.

\section{CONCLUSIONS}

The involvement of the optical measuring techniques in the Physics syllabus design for all engineering specialities as well as in the extracurricular activities contributes to the:

- updating of Physics contents, concerning Optics topics,

- linking of Optics contents with engineering profile tasks,

- increasing motivation regarding speciality problems using advanced technologies,

- strengthening of habits and skills related with the engineering specialities, adapted to the specific features of each speciality,

The didactic-system design based on the discoveries of the up-to-date pedagogical trends enables the formation and training of more comprehensive and qualified graduates in accordance with the modern world requirements and the existing social conditions. All these aspects contributes to the achievement of an excellent graduate.

\section{SUGGESTIONS}

It is suggested to

- continue the involvement of optical measuring techniques in the syllabus design of the different engineering specialists,

- deepen in the applications of the optical measuring techniques as appropriate contexts for the Optics topics development in the different engineering specialities.

- deepen in the study of the most recent discoveries of up-to-date pedagogical trends as suitable theoretical basis for the pedagogical practices, strategies and suggestions concerning Optics. 


\section{BIBLIOGRAPHY}

1. Afanasiev, A. M., et al. Prácticas de laboratorio sobre resistencia de materiales. MIR, Moscú, 1978.

2. Ausubel, D. P. et al. Psicologia Educativa. Un punto de vista cognoscitivo. Ediciones Trillas. Mexico. 1997

3. Colectivo de autores. Programa de la disciplina Física para la carrera de Ingeniería Civil, Industrial, Mecánica. MES, Habana, 1990.

4. Colectivo de autores. CEPES. UH. Tendencias pedagógicas contemporaneas. El Poira Editores e Impresores. SA. Bogota. 1996.

5. Diaz Barriga, F Fernández, G. Estrategias docentes para un aprendizaje significativo. Una interpretación constructivista. Mc Graw Hill. Mexico. 1997.

6. García, A. et al. Conferencias del curso de posgrado "Tendencias actuales en la enseñanza de la Física", ISPJAE, Cuba, 1995.

7. González, O. El enfoque histórico-cultural como fundamento de una concepción pedagógica. CEPES. Universidad de La Habana. 1993.

8. Leontiev, A. N. Actividad, conciencia y personalidad. Editorial Pueblo y Educación. La Habana. 1981.

9. Novak, J. "El papel fundamental de la teoría del aprendizaje en una teoría de la educación". En Teoría y Práctica de la Educación. Alianza. Madrid. 1988.

10. Tobio, J. M. Ensayos no destructivos aplicados a la construcción. Reverte, España. 1969.

11. Silovsky, K. Métodos experimentales para el estado tensional. Universidad de Oriente, Cuba, 1975.

12. Vigotski, L. S. Historia del desarrollo de las funciones psíquicas superiores. Editorial Científico Técnica. Habana. 1987. 